\title{
A imprensa angolana no âmbito da história da imprensa colonial de expressão portuguesa*
}

\author{
Antonio Hohlfeldt** \\ Caroline Corso de Carvalho***
}

\section{Resumo}

O artigo busca compilar dados variados sobre a história de Angola, desde sua condição de colônia portuguesa, a partir do século 15, até o momento presente, para contextualizar a história do desenvolvimento da imprensa naquele território. Surgida no século 19, como consequência de uma decisão do governo colonial que, até então sempre interditara tal iniciativa, a imprensa se concretizou a partir de um boletim oficial que logo abriu caminho para publicações ditas independentes. Se a primeira geração de jornalistas em Angola era constituída de homens europeus brancos, funcionários públicos deslocados para a colônia ou exilados politicamente, a segunda geração já é formada por homens naturais de Angola, o que possibilita as primeiras manifestações independentistas. A síntese histórica que pretendemos encerra-se com a imposição da ditadura salazarista. Ela parte de levantamentos feitos no acervo da Biblioteca Pública Municipal do Porto e de pesquisa bibliográfica. O que se evidencia é que, embora hoje em dia devidamente preparada para enfrentar os desafios tecnológicos, a mídia angolana ainda enfrenta aquele que foi sempre seu maior desafio: a censura.

Palavras-chave: História da imprensa. Imprensa angolana. Imprensa colonial. Teoria do Jornalismo. História do Jornalismo.

* Trabalho apresentado no GP História do Jornalismo, do XI Encontro dos Grupos de Pesquisa em Comunicação, evento componente do XXXIV Congresso Brasileiro de Ciências da Comunicação, na UNICAP, Recife, de 3 a 6 de setembro de 2011, posteriormente revisado e ampliado.

** Professor do Programa de Pós-Graduação em Comunicação Social, Faculdade de Comunicação - FAMECOS, Pontifícia Universidade Católica do Rio Grande do Sul-PUC, Porto Alegre-RS, Brasil. Presidente da INTERCOM nos triênios 2008-2011 e 2011-2014; ex-membro do Conselho Consultivo da SBPJor - Sociedade Brasileira de Pesquisadores em Jornalismo; pesquisador do CNPq; membro do Instituto Histórico e Geográfico do Rio Grande do Sul. email: a_hohlfeldt@yahoo.com.br *** Estudante de Graduação, curso de Jornalismo, Faculdade de Comunicação Social, Pontifícia Universidade Católica do Rio Grande do Sul, bolsista de Iniciação Científica, Porto Alegre-RS, Brasil. E-mail: caroline.corso@hotmail.com 


\section{The Angolean press inside the colonial press history of Portuguese expression \\ Abstract}

This article makes a review of different studies about the Angola's history, since the 15 th. century, till the present moment, to contextualize the development of the country and of the press in this territory. The Angolean press begun in 19th. century, after a decision of the Portuguese government - it begins like an official bulletin, but this bulletin open the doors to the free press. If the first generation of journalists are composed by European and white peoples, political exiled or envoyed to the colony, like public officers, the second generation is constituted by native men, which produce the first examples of independentists thoughs. The synthesis of this experience ended with the salazarian dictatorship. The study is developed on the Porto's Public Library and a specialized bibliography. The conclusion after the study is that even the Angolean midia has a very modern degree of technology suffer the old problem of his entire life: the censureship.

Keywords: Press history. Press in Angola. Colonial press. Journalism's theory. Journalism's history.

\section{La prensa angolana en el contexto de la prensa colonial de expressión portuguesa \\ Resumen}

El articulo hace una compilación de estudios variados sobre la historia de Angola, desde su condición de colonia portuguesa, después del siglo 15, hasta el momento presente, para contextualizar la historia del desarrollo de la prensas en este territorio. Empezada en el siglo 19, como consecuencia de una decisión del gobierno colonial que, hasta entonces, siempre interditara tal iniciativa, la prensa angolana se ha concretizado a partir de una publicación oficial que ha abierto los caminos para las publicaciones independientes. Si la primera generación de periodistas en Angola era formada por europeos blancos, funcionarios públicos enviados a la colonia o exiliados políticos, la segunda generación es ya constituida por nativos de Angola, lo que posibilita las primeras manifestaciones de la independencia. La síntesis histórica que se intenta se termina con la imposición de la dictadura salazarista. El estudio ha sido desarrollado a partir del acervo de la Biblioteca Pública Municipal do Porto y la lectura de una bibliografía especializada. Aunque la media angolana de hoy experimente un grande desarrollo tecnológico enfrenta aún el desafío más duro desde siempre: la censura.

Palabras clave: Historia de la prensa. La prensa angolana. La prensa colonial. Teoría del periodismo. Historia del periodismo. 


\section{Introdução}

imprensa em Angola surgiu no século 19, como consequên-
cia de uma decisão do governo colonial que, até então
sempre interditara tal iniciativa, e se concretizou a partir de um boletim oficial que logo abriu caminho para publicações ditas independentes.

Baseada em pesquisa bibliográfica e de estudo de documentos por meio levantamentos feitos no acervo da Biblioteca Pública Municipal do Porto, a pesquisa tem como objetivo compilar dados variados sobre a história de Angola, desde sua condição de colônia portuguesa, a partir do século 15, até o momento presente, para contextualizar a história do desenvolvimento da imprensa naquele território.

\section{O nascimento de Angola}

O continente africano é considerado o berço da humanidade. $\mathrm{O}$ atual território de Angola foi habitado, segundo historiadores, desde o período do Paleolítico Superior. Tratava-se de povos coletores, os chamados Bosquímanos, pigmeus, que deixaram seus traços por meio de pinturas rupestres. Seus descendentes, contudo, tiveram seus territórios invadidos e foram empurrados para o sul, pelos bantus, provindos do norte, no século VI d.C. Esses eram caçadores e já dominavam algumas técnicas de metalurgia, cerâmica e agricultura. Ao longo da história angolana, houve sucessivos movimentos de migração semelhante, inclusive durante o século 20, sem que esses novos movimentos modificassem, essencialmente, aquilo que se configurara nos séculos anteriores, pelo menos até o século 13. A chegada dos europeus colonizadores ocorreu por meio da expedição de Diogo Cão, em 1482, a mando do rei Dom João II, de quem ele era escudeiro. Diogo Cão desembarcou na foz do rio Congo, atual Zaire.

Por volta de 1400, organizara-se o Reino do Congo, ao mesmo tempo em que, ao sul, estruturava-se o Reino do Ndongo. $\mathrm{O}$ rei do Congo era chamado de Mani, enquanto o rei de Ndongo 
denominava-se Ngola. Embora os portugueses tenham se estabelecido originalmente na região do Congo, de etnia kumbundi, foi do reino de Ngola que a região herdou sua denominação geográfica de Angola.

Diogo Cão foi bem recebido. Logo o rei local se converteu ao cristianismo e firmou tratados comerciais com o rei de Portugal, adotando divisão política do território semelhante à da metrópole. $O$ primeiro governador lusitano da região foi Paulo Dias de Novais, que procurou explorar o território agricolamente. Mas a conquista do sul foi difícil, sobretudo durante o reinado da rainha Njinga Mbandi (1581-1663), conhecida como Rainha Jinga, que formou uma verdadeira confederação contra os lusos, a partir de 1635. Os portugueses, liderados por Manuel Cerveira Pereira, conseguiram vencer os nativos, sucessivamente, em 1665 (Congo), 1671 (Ndongo) e 1681 (Matamba), fundando Benguela que, com Luanda, fundada ao norte do território, tornar-se-ia ponto de referência para o comércio, em especial, o tráfico de escravos.

Durante a ocupação filipina de Portugal (1580-1640), os holandeses, a exemplo do que fizeram com o Brasil, invadiram a região, em 1641, ocupando boa parte do litoral, mas foram expulsos em 1648, por uma expedição organizada na colônia sul-americana (não esquecer que, aqui, os holandeses haviam sido derrotados em 1645), chefiada por Salvador Correia de Sá, na batalha do forte Massango (PONTE, 2011; GONÇALVES, 1964) ${ }^{1}$.

No início do século XVIII, enfim, Portugal já dominava completamente a região. De modo geral, os historiadores dividem a história angolana em quatro grandes períodos: o da pré-história; o período pré-colonial, iniciado com a chegada dos bantus e que vai até a presença dos portugueses, ambos aqui mencionados rapidamente; o período colonial, que se desenvolve até 1975 , e o período independente, que é o atual.

Quanto ao período colonial, ele é subdividido em a) época da conquista portuguesa, até o século 18 ; b) época do tráfico

\footnotetext{
${ }^{1}$ Além do texto de Helder Fernando do Pinto Correia Ponte e de J. J. Gonçalves, mencionados acima, consultaram-se diferentes arquivos da rede internacional de computadores, que vão mencionados nas referências bibliográficas, consolidando-se dados para esta síntese.
} 
colonial, que se desenrola até 1888 , com a promulgação da Lei Áurea no Brasil, que estanca formalmente o tráfico, embora ainda se enviassem muitos negros para os Estados Unidos; e c) a época da exploração dos produtos coloniais, como mel, borracha, açúcar, café, algodão, tabaco, milho, diamantes, ferro e petróleo, que se encerra com a independência (PONTE, 2011).

\section{A Comunicação durante o momento colonial}

A Comunicação define-se por diversas interfaces. Na África, suas características englobam os elementos daquelas culturas autóctones. A população desenvolvera, segundo seus costumes, diferentes modos de se comunicar, por sinais, cantos e gritos, entre outros: ocorria, pois, a transmissão verbal, direta, ou por estafetas; a transmissão mímica; a transmissão ideográfica; a transmissão sônica, e pouco mais, devendo creditar-se, portanto, à ação europeia, a introdução de novos processos (GONÇALVES, 1964).

As regras básicas da colonização estabelecidas desde a metrópole eram únicas. Havia um ponto positivo nisso, sob a ótica de uma só tática e política; mas também um ponto negativo, pois Portugal não distinguia políticas de desenvolvimento diferenciado para as suas colônias, o que lhes provocou atrasos consideráveis (HOHLFELDT, 2008). Essa ideia geral é, por vezes, contestada por alguns historiadores, como se verifica no texto de Maria da Conceição Neto (1997), para quem a administração portuguesa teve um tratamento diferenciado entre as colônias.

Seja como for, enquanto Portugal experimentou sua primeira imprensa em torno de 1626, a primeira máquina em Angola foi adquirida por Joaquim António de Carvalho Menezes, nato do país, apenas em 1842. Enviada para Luanda, de navio, curiosamente o barco afundou, aparentemente por orientação da metrópole (GONÇALVES,1964). Em 1845, o Governador Geral, Pedro Alexandrino da Cunha, importa outra prensa, e a partir de 13 de setembro de 1845, sob o signo da oficialidade, publica-se o primeiro periódico angolano, o Boletim Official, na capital, Luanda.

Alguns autores, como Licurgo Costa e Barros Vidal e Lawrence Hallewell, afirmam que, nos séculos 16 e 18, já teria existido 
algum prelo em Angola (QUEIROZ, 2010)². No caso de Barros Vidal, seriam dois prelos, instalados, respectivamente, em Luanda e em São Salvador do Congo (Mbanza Kongo). No caso de Hallewell, a referência seria aos primeiros jesuítas que, a exemplo do que fora praticado em Goa, teriam levado consigo um prelo. Contudo, diz ele, nenhum pesquisador ou historiador até hoje, em especial Júlio de Castro Lopo, que é seu grande estudioso, jamais comprovou a veracidade de tais informações ou encontrou provas documentais que sustentassem tais hipóteses.

No caso de Lopo, ele divide a história da imprensa angolana em três fases:

a) fase da imprensa oficial, a partir de 13 de setembro de 1845, quando circula a primeira edição do Boletim Oficial;

b) fase da imprensa independente, a partir de 1852, quando se faz a edição única do Almanak Statístico da Província d'Angola e suas Dependências, seguindo-se o jornal literário Aurora, de 1856 e, enfim, o primeiro jornal político de combate ao colonialismo, A civilização da África portuguesa, dos advogados António Urbano Monteiro de Castro e Alfredo Júlio Côrtes Mântua. Esse jornal abriu a série de periódicos eminentemente políticos que se seguiriam; a esse tipo de imprensa, alguns estudiosos denominam de imprensa livre (CRUZ; SILVA, 2010);

c) fase da imprensa industrial ou profissional, a partir de 16 de agosto de 1923, quando começa a circular o jornal Província de Angola, fundado por Adolfo Pina, ainda que o primeiro jornal com tais características tenha sido o Jornal de Benguela, de 1912, criado por Manuel Mesquita, primeiro a possuir tipografia própria. É importante, nesta fase, também, a contribuição de Alfredo Troni, que editou, sucessivamente, três periódicos, Jornal de Luanda (1878), Mukuarimi (1888) e Conselhos de Leste (1891),

\footnotetext{
${ }^{2}$ Arthur Queiroz refere-se à obra História e evolução da imprensa brasileira (1940), de Licurgo Costa e Barros Vidal, editada no Rio de Janeiro, e Laurence Hallewell (1982), traduzida no Brasil.
} 
sendo que Mukuarimi foi o primeiro a utilizar uma expressão angolana, que queria dizer o maldizente, o fofoqueiro;

d) por outro lado, Hohlfeldt (2009) defende que é necessária uma quarta etapa, posterior aos acontecimentos do 25 de abril de 1974, que se desdobraram e se concretizaram em projetos independentistas das colônias, com consequências mais do que evidentes ${ }^{3}$.

Fica claro, a partir desses estudos, que a relação entre Jornalismo, literatura e militância independentista, frente a Portugal, caminham juntos nos países africanos de língua portuguesa, especialmente em Angola.

No entanto, durante séculos, o interesse pela província de Angola foi muito reduzido entre os metropolitanos. Portugal estava mais preocupado com o Brasil, por exemplo. Antes de 1845, data do nascimento do primeiro periódico daquela colônia, apenas se assinala a presença de publicações recebidas da metrópole ou do estrangeiro em Angola, publicações essas levadas pelos missionários, pelos holandeses que ocuparam Luanda ou pelos escassos colonos que ali fixavam morada (GONÇALVES,1964).

Mas com o passar do tempo, e depois da invasão dos holandeses na região, a presença portuguesa em Angola foi ganhando expressão: novos colonos, mais investimentos, e conseqüentemente, mais raízes humanas e econômicas.

\footnotetext{
${ }^{3}$ A síntese que aqui se apresenta faz parte de pesquisa iniciada em estágio Pós-Doutoral, desenvolvida a partir do primeiro semestre de 2008, junto à Universidade Fernando Pessoa, do Porto, patrocinada pela CAPES. O material pesquisado, que constitui o corpus da pesquisa, encontra-se depositado na Biblioteca Pública Municipal do Porto, a que o autor teve acesso, durante estes estudos. Todos os jornais disponíveis foram fichados e identificados, digitalizando-se todas as primeiras edições, disponíveis em http://pucrs.br/famecos/nupecc. O estudo sobre o Jornalismo angolano faz parte, assim, de um contexto maior, que é o do Jornalismo luso-brasileiro, aí incluído o das antigas colônias de expressão portuguesa. A pesquisa, nesta segunda etapa, vem ganhando apoio do CNPq, através de bolsa de produtividade. Pretende-se, com este estudo, propiciar um estudo integrado do desenvolvimento do Jornalismo luso-brasileiro, aproximando seu desenvolvimento nos diferentes territórios e a metrópole portuguesa, com especial ênfase às relações entre o Jornalismo brasileiro e o das antigas colônias.
} 


\section{O Boletim Oficial de Angola}

A primeiro edição do Boletim do Governo-Geral da Província de Angola apareceu no dia 13 de setembro de 1845. Com sua publicação, dava-se cumprimento ao disposto no decreto de 7 de setembro de 1836, que ordenava se publicar em todas as províncias boletins oficiais, sob a inspeção de cada governo local (LOPO, 1964).

O Boletim Oficial de Angola, como de resto se verificou com alguns dos publicados em outras províncias, com exceção de Goa, foi, no início, o único órgão de Comunicação social existente. Além das disposições legais, divulgava também notícias e anúncios (LOPO, 1964), que se exteriorizavam em prosa literária e em versos de maior ou menor inspiração, ou de ideais sonhados:

Onde a onde[sic], até grave magistrado judicial publicava uma poesia no Boletim Oficial, largando a toga de juiz para dedilhar a lira dos poetas

Até aqueles que tenham o gosto de saber de certos pormenores da vida social desses tempos, encontrarão na folha governamental a reportagem do crime, bizarros anúncios particulares e comerciais, notícias e críticas teatrais, bem como noticias da chamada nossa senhora sociedade [...] (LOPO, 1964).

No órgão oficial, de acordo com Júlio Castro Lopo (1964), divulgavam-se avisos de rifas de objetos que, entre si, organizavam os moradores de Luanda; declarações de credores a ameaçarem os devedores, a quem indicavam por iniciais e apelidos, com a promessa de o fazerem depois no boletim oficial, com os respectivos nomes e apelidos por extenso, se não solvessem as dívidas reclamadas por meio da imprensa; participações de casamentos, nascimentos e óbitos; declarações de comércio ao público geral etc; avisos de partidas e chegadas de navios e outras embarcações; avisos de pessoas partindo para o Reino ou para o Brasil, que assim se despediam de conhecidos e amigos, constituíam também seu conteúdo.

Para tudo prestava ou parecia se prestar o Boletim Oficial, que pouco a pouco deixou de se ocupar das questões não oficiais, até vir a confinar-se exclusivamente aos problemas governamentais, tendo começado com uma folha apenas (GONÇALVES, 1964). 
Após o advento do Boletim Oficial, surgiram outras publicações, embora sem a periodicidade que caracterizasse um jornal, como foi o caso do Almanak Statístico da Província de Angola e suas dependências, publicado em 1852, e já citado.

Quanto aos jornais literários, também como se disse, a primazia coube ao semanário A Aurora - de curta duração - fundado em 1856, e cuja primeira edição saiu em 31 de maio, circulando até 7 de junho de 1856 (GONÇALVES, 1964).

Outros jornais, algumas revistas e boletins, assim como anuários e anais se sucedem, podendo-se dizer que, em geral, sua duração era efêmera, dado o condicionamento em que foram criados e a instabilidade do mercado local da informação (GONÇALVES, 1964).

Assim, ao longo de mais de 20 anos, o Boletim Oficial foi a única publicação periódica que circulou com regularidade em Angola. Por isso, os colonos começaram a designar por imprensa livre os periódicos saídos de tipografias particulares, distinguindo-os da folha impressa do governo.

\section{O desenvolvimento da imprensa}

Com o aparecimento da primeira edição do periódico de Luanda, A Civilização da África Portuguesa, em 1866, iniciou-se efetivamente o segundo período do Jornalismo angolano. Por mais que se tenha continuado a publicar, durante mais alguns anos, anúncios, comunicados particulares e artigos no jornal oficial, ele deixou de estar sozinho no território. Passou a existir a chamada imprensa livre. Era esse o Jornalismo episódico, feito por criaturas geralmente das mais ilustradas no meio social e que tinham outras profissões definidas, mas para as quais se apresentava a tarefa de escrever para o público (LOPO, 1964).

O projeto do nacionalismo angolano é iniciado pela edição dos jornais $O$ Pharol do povo, Tomate e $O$ desastre (CRUZ E SILVA, 2010). Se os primeiros periódicos eram produzidos por homens brancos, portugueses, a maioria dos quais exilados políticos, com uma ideologia republicana, contrária, pois, ao governo português que ainda era monárquico, os jornais posteriores já foram 
idealizados e editados por uma segunda geração constituída por pretos ou mestiços, mas todos nascidos na África. São os casos de José de Fontes Pereira e de Mamede Santana e Palma, a que se seguirão João da Ressurreição Arantes Braga, Inocéncio Mattoso da Câmara, João Ignacio de Pinho ou Joaquim Dias Cordeiro da Matta, dentre outros.

O primeiro jornal editado depois do Civilização da África Portuguesa parece ter sido O Commércio de Loanda, em 1867. Contudo, não se pode garantir a sucessão e a datação desses jornais, pelas dificuldades encontradas na pesquisa, pois, na época, não era obrigatório o depósito legal de tais peças periódicas nas bibliotecas públicas portuguesas, o que tornou o estudo dos raros autores e pesquisadores, quase impossível, sem ter contato adequado com os exemplares publicados e eventualmente guardados.

Em 1870, é lançado o jornal O Mercantil. Como o Commércio de Loanda (1867), foi dos primeiros a possuir tipografia própria, segundo Júlio de Castro Lopo (1964). O Mercantil alcançou 18 anos de existência, motivo para ser apontado como um dos jornais angolanos do fim do século 19 com maior longevidade. Adolfo Pina, que responde por ele, editara um boletim da Associação Comercial de Luanda durente muitos anos. Conhecia a profissão e tinha apoio inclusive para os anúncios divulgados em seu jornal.

A imprensa se iniciou, em Angola, pois, sob o signo da lei e do público, para dar a conhecer informações de natureza vária. Mas o Boletim Oficial acabou perdendo seu caráter de órgão de informação comunitária, à medida que se ia implantando a imprensa independente.

Ainda assim, os periódicos de grande atividade política aparecem e desaparecem meteoricamente, por força da pressão governamental. Alguns órgão políticos repetem o debate metropolitano, como consequência do transplante, para Angola, das rivalidades entre progressistas e regenerados, monárquicos e republicanos etc. Depois, há um período em que as publicações técnicas circulam em grande quantidade, o que se verifica com os boletins e as revistas dos vários serviços provinciais. Mais próximo dos anos 1860, a imprensa noticiosa apresenta-se em busca de estabilização, em vias mesmo de institucionalização. 
Por outro lado, a eclosão de acontecimentos como os de 1891, com as pressões internacionais sobre as colônias portuguesas, leva a imprensa angolana a buscar melhores e mais vastos noticiários. Ao mesmo tempo, aumenta o número de informações transmitidas desde as capitais mundiais. Assim, por exemplo, a Companhia do Caminho de Ferro de Benguela começa a publicar, em Londres (visando, naturalmente, as suas atividades em Angola) o jornal Benguela News.

A sociedade do século 19, em Angola, era dividida entre civilizados e não civilizados. Civilizados eram os brancos, independentemente da sua condição social, econômica e acadêmica; mestiços e negros escolarizados que tivessem hábitos e costumes europeus e abandonado o modo de vida africano. Não-civilizados eram os negros que mantinham os hábitos autóctones, isto é, aqueles que, nascidos no ultramar, de pai e mãe indígenas, não se distinguissem pela sua instrução e costumes do comum de sua raça (MACÊDO; CHAVES, 2007).

Muitos dos periódicos que se publicavam em Angola não tinham o necessário número de assinantes, pois eram vendidos avulsamente, nas localidades onde eram editados. Em Angola, fez-se Jornalismo episódico e de amadores, por profissionais das mais variadas condições sociais, tais como empregados comerciais, agricultores, negociantes e lojistas, magistrados judiciais, médicos, professores, missionários e clérigos, veterinários, oficiais da marinha mercante e de guerra, militares e até indivíduos que permaneciam em Angola em situação de degredados, mas gozando de benefícios de fianças ou proteções sempre razoáveis (LOPO, 1964).

A edição desses jornais se dava por diversos motivos. Interesses particulares, literários, mercadológicos ou políticos permeavam as publicações:

Os periodistas redigiam as folhas com finalidades diversas, como recreação literária, por expansão intelectual, por temperamento de escritores ou por vocação conjectual ou verdadeira; para propaganda política ou por partidarismo local; para a defesa de interesses regionais, comerciais, agrícolas e industriais; por mercantilismo, com feição noticiosa a favor de determinados interesses particulares; por motivos e intuitos panfletários, em que a pena ora se transformava em espada leal de combate denodado, ora em punhal de assaltante grosseiro e traiçoeiro (LOPO, 1964). 
Não obstante, esse Jornalismo episódico e de amadores foi muito importante na colônia, pelos valores culturais que nele se revelaram ao longo dos anos. Alguns desses jornalistas chegaram a publicar inclusive nos grandes periódicos da metrópole (LOPO, 1964).

O Jornalismo industrial e, consequentemente profissional, só foi aparecer e ter caráter definitivo em 16 de agosto de 1923, com a fundação do jornal A Província de Angola. Quando o jornal foi fundado, já existia, desde 3 de julho de 1912, o semanário Jornal de Benguela. Esta publicação, contudo, ficou isolada e não teve sequência. Daí considerar-se seu início efetivo apenas com $A$ Província de Angola (LOPO, 1964).

\section{Ligações entre o Jornalismo e a literatura}

A imprensa angolana era centralizada quase que exclusivamente em dois centros urbanos, Luanda e Benguela. A literatura, que começa a reivindicar sua especificidade nacional, ao mesmo tempo em que aponta para a necessidade de autonomia da colônia, não se choca, antes acompanha, o texto jornalístico e, de certa maneira, nasce e se desenvolve com ele. Os jornais sempre dedicaram espaço às colaborações literárias e, por isso mesmo, a figura do intelectual ganha inquestionável relevo, sendo o jornalista e o literato, muitas vezes, a mesma pessoa (MACÊDO; CHAVES, 2007).

O escritor Pepetela, em texto publicado no site da União dos Escritores Angolanos (2003), explica que havia uma intensa atividade jornalística, mesmo que por meio de periódicos de vida efêmera, sobretudo em língua portuguesa, mas também em idiomas nativos. Tinham forte carga social e política, aproveitando a relativa liberdade de expressão existente num momento de grandes lutas em Portugal, já que a monarquia dava nítidos sinais de esgotamento, e um novo sentimento republicano, crescentemente reforçado, se afirmava (final do século 19). Os periódicos eram fechados, suspensos ou proibidos constantemente pelo poder político, mas reapareciam sob novas roupagens ou títulos. Exemplo disso é a constância com que certos nomes de editores se apresentavam 
como responsáveis pelas publicações. Um grupo de intelectuais criava um jornal, do qual se publicavam duas ou três edições. Em seguida, o jornal era proibido, e um ou dois meses depois, o mesmo grupo criava um novo periódico, com a mesma linha editorial, mas com designação diversa, até voltar a ser proibido.

Essa intelectualidade, mistura cultural e racial, era extremamente crítica da colonização portuguesa e do pouco caso que o Estado fazia sobre a necessidade de desenvolvimento do território e da instrução e tratamento sanitário da população africana.

Neste sentido, o Jornalismo, a literatura e a política foram frentes de oposição ao colonialismo português durante o século 19 e o início do século 20, nas então colônias portuguesas em África. A palavra escrita firmou-se como espaço de campanha e luta pela autonomia.

No caso da literatura, deve-se recordar que o primeiro livro de autor autóctone é Espontaneidades da minha alma (1849), de José da Silva Maia Ferreira, conjunto de poemas a que se seguiu a noveleta Nga Muturi, de Alfredo Troni (1882). De um lado, pois, um poeta angolano; de outro, um prosador português mas que adere ao programa independentista de Angola. $\mathrm{O}$ segundo também faz parte da história do Jornalismo. E se o mestiço Maia Ferreira não pratica Jornalismo, é na gráfica da imprensa oficial do boletim do governo que seu livro se imprime.

A apropriação de expressões em kikongo, umbundo e, principalmente, quimbundu traduz a luta de resistência contra o colonialismo, presente tanto na literatura quanto no Jornalismo, que se publica com artigos ou páginas e até títulos em idiomas africanos.

Tanto A aurora quanto A Civilização africana, Jornal de Luanda como $O$ mercantil, todos incluem poemas, textos curtos literários, suplementos e páginas literárias em suas edições pequenas - não mais de quatro páginas, raramente seis (JACOB, 2010).

\section{Contemporaneidade}

A evolução jornalística de Angola, segundo Júlio de Castro Lopo, em Jornalismo de Angola (1964), dependeu, dentre outros fatores, do incremento da colonização europeia, do desenvolvimen- 
to do comércio interno e do comércio exportador. Na medida em que o território foi progredindo no intercâmbio com a Europa e com o aumento das exportações de gêneros agrícolas e minerais, igualmente foram se estabelecendo as tipografias e os periódicos: em síntese, a urbanização permitiu o desenvolvimento do Jornalismo, como se conhece em todo o mundo.

Hoje em dia, Angola tem cerca de 16 milhões de habitantes e um único grande diário, com dez mil exemplares/dia (COSTA e CÂNDIDO, 2011). Uma absoluta minoria de pessoas lê jornais e os jornalistas ainda enfrentam problemas com a censura, perseguições e prisões, por parte do governo, ainda que a situação tenha melhorado, formalmente, a partir da nova constituição do país, que permitiu a abertura de novas publicações, depois de ter nacionalizado todos os meios Comunicação, após a vitória da revolução. Contudo, mais recentemente, jornais católicos foram fechados; o jornalista António Manuel Jojó foi assassinado em 22 de outubro de 2010 (DESPERTAR, 2010), desconfiando-se que a mando de algumas autoridades ou de segmentos a elas ligados; o jornalista William Tonet ficou impedido de deixar o país depois de publicar críticas ao governo no jornal Folha 8 (REPORTERS SANS FRONTIÈRE, 2009); e em 2010 Angola foi rebaixada

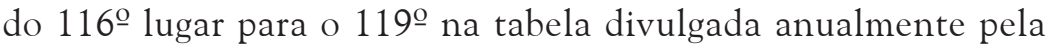
organização independente Repórteres sem fronteiras (2010).

Ao mesmo tempo, com a ajuda do Brasil, o país implanta a televisão digital (OBSERVATORIO DA IMPRENSA, 2011) e tenta desenvolver as mais modernas tecnologias para os seus processos comunicacionais. Angola ainda enfrenta, contudo, problemas políticos nas disputas entre a antiga UNITA e o MPLA, que se refletem, justamente, num dos aspectos mais sensíveis da realidade nacional que é, justamente, o Jornalismo.

Do que se lê, enfim, pode-se observar que embora haja um forte processo de atualização tecnológica, Angola continua sofrendo do maior mal que marca a história de seu Jornalismo: a falta de liberdade e a existência da censura. 


\section{Referências}

CONCEIÇÃO, Joaquim Paula da. A Comunicação angolana. Anuário Internacional de Comunicação Lusófona 2005, Lisboa, LUSOCOM / SOPCOM. 2005.

CONCEIÇÃO NETO, Maria da. Ideologias, contradições e mistificações da colonização de Angola no século XX. Lusotopie, p. 327-359, 1997. Disponível em: http://www.lusotopie.sciencespobordeaux.fr. Acesso em: 05 fev.2011.

COSTA, Dani; CÂNDIDO, Teixeira, António Tomás. Vivemos numa sociedade que premeia o consumo, mas não a produção. O País on line, 6 de julho de 2011. Disponível em: http://www.opais.net;pt/ opais/?det $=18349 \&$ id $1647 \&$ mid $=$. Acesso em: 06 jun.2011.

CRUZ E SILVA, Rosa. O nacionalismo angolano: um projecto no século XIX através de três periódicos da época: $O$ Pharol do povo, Tomate e $\mathrm{O}$ desastre. Disponíve em: http://www. ueangola.com/index.php/cfriticas-e- ensaios/item/72-construindo-a-hist\%C3\%B3ria-angolana-as-fontes-e-a-sua-interpreta\%C3\%A7\%C3\%A3o.html. Acesso em: 05 fev. 2011.

GONÇALVES, J. J. A informação em Angola - Alguns subsídios para o seu estudo. Lisboa, sem indicação de editora. 1964.

HALATA, Dionísio. Sobre o Jornalismo angolano. Disponível em: http:// www.webartigos.com/articles/53052/1/Sobre-o-Jornalismo-Angolano/pagina1. html. Acesso em: 05 fev. 2011.

HOHLFELDT, C. A. Imprensa das colônias de expressão portuguesa: primeira aproximação. Comunicação $\mathbb{\&}$ sociedade, São Paulo, Universidade Metodista de São Paulo, n. 51, p.135-154, 2009.

HOHLFELDT, C. A. Imprensa das colônias de expressão portuguesa: principal bibliografia. In: VI Encontro Nacional de Pesquisadores em Jornalismo, São Paulo, SBPJor. 2008.

JACOB, Sheila Ribeiro. A imprensa livre e o despertar da vida literária angolana no século XIX. In: Miscelânea - Revista de Pós-Graduação em Letras, Assis, UNESP, v. 8, jul./dez. 2010.

LOPO, J. C. Jornalismo de Angola - Subsídios para a sua história. Luanda: Centro de Informação e Turismo de Angola, 1964.

MACÊDO, Tania; CHAVES, Rita de Cássia N.; SANTILLI, Maria Aparecida. Literaturas de língua portuguesa: marcos e marcas - Angola. São Paulo: Arte \& Ciência. 2007. 
MELO, A. B. A influência do Brasil no jornalismo de Angola. Nova Iguaçu: Semana Ilustrada, 1985.

OBSERVATÓRIO DA IMPRENSA. Brasil finaliza fase de testes de TV digital em Angola, edição de 13 de abril de 2011, Ano 16, nº 637. Disponível em: http://observatoriodaimprensa.com.br. Acesso em: 13 abr.2011.

OLIVEIRA, Jurema José de. As literaturas africanas e o Jornalismo no período colonial. Disponível em: www.omarrare.uerj.br/numero8/pdfs/jurema.pdf . Acesso em: 5 mar. 2011.

PEPETELA. Algumas questões sobre a literatura angolana. Palestra proferida na "Maka de quarta-feira", da União dos Escritores Angolanos no dia 18 de junho de 2003. Disponível em: http: www.uea-angola.org barra artigo. $\mathrm{cfm}$ ?ID=173. Acesso em: Acesso em: 5 mar. 2011.

PONTE, Helder. Introdução ao estudo da história de Angola. Disponível em: http://introduestudohistangola.blogspot.com.br . Acesso em: 01 mar. 2011.

QUEIROZ, Artur. A imprensa em Angola no século XIX. Jornal de Angola-online. Disponível em: http://jornaldeangola.sapo.ao/17/0/a_imprensa_em_ angola_no_seculo_ixi. Acesso em:

SILVA, G. Jorge. Telegrafia sem fio. Dúvidas: quem fez realmente a primeira transmissão via rádio? 23 jun. 2003. Disponível em: http://www.landelldemoura.qsl.br/teleg_sem_fios_portugal.htm. Acesso em: 07 fev. 2011.

\section{Sites}

http:// www.lusoafrica.net/v2/index.php?option $=$ com_content $\&$ view $=$ article $\&$ $\mathrm{id}=85$ \& Itemid $=106$

http:// www.lusoafrica.net/v2/index.php?option $=$ com_content $\&$ view $=$ article $\&$ $\mathrm{id}=85$ \& Itemid $=102$

http://www.angolaembassy.gr/Portugues/HISTORIA.htm

http://www.terrasdeveracruz.freewebpages.org/angola1.htm

http://amota.wordpress.com/2010/10/22/atentado-em-angola-a-vida-do-jornalista-antonio-manuel-jojo/

http://fr.rsf.org/spip.php?page =imprimir_articulo\&id_article $=32929$

http://www.radioecclesia.org/index.php?option $=$ com_content\&view $=$ article \&i $\mathrm{d}=2649$ :angola-volta-a-descer-na-tabela-mundial-de-liberdade-de-imprensa $\& c$ atid $=132$ : internacionais\&itemid $=484$ 